\title{
The Importance and Trickiness of Definition Strategies in Legal and Political Argumentation
}

\author{
Douglas Walton $^{1} \&$ Fabrizio Macagno ${ }^{2}$ \\ ${ }^{1}$ Centre for Research in Reasoning, Argumentation and Rhetoric (CRRAR), University of Windsor, Windsor, \\ Canada \\ ${ }^{2}$ ArgLab, Institute of Philosophy (IFILNOVA), Universidade Nova de Lisboa, Lisbon, Portugal \\ Correspondence: Douglas Walton, Centre for Research in Reasoning, Argumentation and Rhetoric (CRRAR), \\ University of Windsor, 2500 University Ave. W., Windsor, Ontario N9B 3Y1, Canada. Tel: 1-519-253-3000 Ext. \\ 2362. E-mail: dwalton@uwindsor.ca
}

Received: November 29, 2014

doi:10.5539/jpl.v8n1p137
Accepted: December 18, 2014 Online Published: February 27, 2015

URL: http://dx.doi.org/10.5539/jpl.v8n1p137

\begin{abstract}
This paper uses argumentation tools to show by means of analyzing nine cases from law and politics how argument strategies using persuasive definitions and quasi-definitions are powerful rhetorical tools of persuasion. By bringing to lightthe argumentation structure found in these examples, it is shown that definitions and redefinitions can have serious legal and political implications. Persuasive definitions and quasi-definitions are modeled as two distinct strategies for altering the relationship between classification and evaluation of a state of affairs. Persuasive definitions are aimed at modifying the relationship between the definiendum and its referent. In quasi-definitions some characteristics of an entity or event leading to a specific value judgment are selected and made accessible, while other conflicting ones are excluded. Reframing an issue is shown to be related to both strategies.
\end{abstract}

Keywords: argumentation, definition, persuasion, framing, manipulation

\section{Introduction}

It is commonly assumed at this point in history that definitions are trivial, and that arguing about definitions is a sign of sophistry that detracts attention from considering the objective evidence relevant to matters of serious concern in a debate, discussion, or evidence-based inquiry. Against this assumption two points need to be made straight away. It only takes a little reflection to realize that definitions are fundamentally important in both science and law. Legal rules always depend on definitions, and many legal rules are in effect proposed definitions. Science has been so successful as a form of evidence-based inquiry precisely because it pays careful attention to framing definitions, often expressing its definitions in mathematical formulas. The example of Euclidean geometry is a widely familiar case in point.

Although there has been a small body of work on definitions in the field of argumentation studies, and since ancient times there has been a recognition that framing careful definitions is a powerful rhetorical strategy, it is still hard to convince people that conducting serious research in argumentation studies on how definitions are used in argumentation is an important and difficult area of research, and that it is a topic of study that has significant implications for disciplines such as law, and for political deliberations and the framing of political policies. In this paper we present and analyze nine cases that demonstrate how assumptions that diminish the importance of definitions are widely off the mark, and that thinking with regard to them needs to be revised.

It is well-known that logic textbooks have offered classification systems for the different kinds of definitions commonly recognized, including stipulated definitions, lexical definitions, precising definitions, theoretical definitions, and persuasive definitions. Although the precise form and contents of such classification systems are disputed, and a wide variety of them have been offered, pursuing the systematic study of the uses of definitions in argumentation has been sadly neglected, with notable exceptions. Recently a study of definitions with a particular focus on persuasive definitions (Macagno \& Walton, 2014) has surveyed the literature and approached the study of definitions from a point of view of a theory of argumentation applied to many examples where definitions are disputed by pitting arguments supporting a particular definition against arguments attacking it. 
The purpose of this paper is to extend the framework of this work by using the analyses of nine cases, to show that definitions can have serious economic and political consequences, and to show how they can be employed in arguments on legal and public policy issues to reframe the issue by redefining a key term. Those in the field of rhetoric are already well aware from their own studies of political debates affecting public policy issues how widespread and how important reframing an issue in this way is as a strategic argumentation tactic. But by exposing some of the argumentation structure around the nine cases of the use of this tactic, it is shown how such arguments about definitions can be modeled using current argumentation tools. The definitions employed as arguments in all of these examples are shown to have serious implications in political discourse, both at the level of policy-making and at the level of the justification of a policy put before the public.

\section{Persuasive Redefinitions}

The act of naming a fragment of reality, called argument by definition by Zarefsky (2006, p. 404) is a form of condensed argument composed of two dimensions: a classification of reality and a value judgment. Stevenson (1937) showed how these two dimensions are combined when he investigated the terms he called "ethical" or emotive. He noted that some words, such as 'peace' or 'war', are not simply used to describe reality by modifying the cognitive response of the interlocutor. They have also the power of directing the interlocutor's attitudes and suggesting a course of action. For this reason, they evoke a different kind of reaction, emotive in nature. As Stevenson (1937, pp. 18-19), put it "Instead of merely describing people's interests, they change and intensify them. They recommend an interest in an object, rather than state that the interest already exists." These words have the tendency to encourage future actions (Stevenson 1937, p. 23; Stevenson, 1938a, pp. 334-335; Stevenson, 1938b, pp. 49-50), to lead the hearer towards a decision by affecting his or her system of interests (Stevenson, 1944, p. 210). Stevenson distinguished between the use of a word (a stimulus) and its possible psychological effects on the addressee's cognitive and the emotive reactions by labeling them as "descriptive meaning" and "emotive meaning" (Stevenson, 1944, p. 54). Applying this distinction reveals how the redefinition of an ethical word is transformed into an instrument of persuasion, a tool for redirecting preferences and emotions (Stevenson, 1944, p. 210):

Ethical definitions involve a wedding of descriptive and emotive meaning, and accordingly have a frequent use in redirecting and intensifying attitudes. To choose a definition is to plead a cause, so long as the word defined is strongly emotive.

The two strategies for "redirecting and intensifying" attitudes are persuasive definition and quasi-definition. In persuasive definitions the evaluative component associated with a concept is left unaltered while the descriptive meaning is modified. In this fashion, imprisonment can become "true freedom" (Huxley, 1955, p. 122), and massacres "pacification" (Orwell, 1946). Persuasive definitions can change or distort the meaning while keeping the original evaluations that the use of a word evokes. Quasi-definitions consist in the modification of the emotive meaning of a word without altering the descriptive one. The speaker can quasi-define a word by qualifying the definiendum without setting forth what the term actually means. For instance, we can consider the following quasi-definition taken from Casanova's Fuga dai Piombi. In this example (1), the speaker, Mr. Soradaci, tries to convince his interlocutor (Casanova) that being a "sneak" is an honorable behavior (Casanova, 1911, p. 112) ${ }^{1}$ :

Case 1

I have always despised the prejudice that attaches to the name "spy" a hateful meaning: this name sounds bad only to the ears of who hates the Government. A sneak is just a friend of the good of the State, the plague of the crooks, the faithful servant of his Prince.

This quasi-definition employed in case 1 underscores a fundamental dimension of the "emotive" meaning of a word, nameley its relationship with the shared values, which are attacked as "prejudices." This account given by the spy shows how describing the referent based on a different hierarchy of values can modify emotive meaning. The value of trust is not denied, but is placed in a hierarchy where the highest worth is given to the State.

Persuasive and quasi-definitions are based on a fundamental principle, which is the practical dimension of definitions. On this view, definitions are instruments for classifying reality, and classification has in turn serious practical implications affecting our actions and decisions. The relationship between definitions and decisions involves the relationship at least among the definiendum, its reference, and the evaluation thereof. In the following two sections we will analyze how these relations can affect our choices and can be modeled using

\footnotetext{
1 "Ho sempre disprezzato il pregiudizio che conferisce un odioso significato al nome di spia: questo nome non suona male che alle orecchie di chi non ama il Governo: uno spione non è altro che un amico del bene dello stato, il flagello dei delinquenti, il fedel suddito del suo Principe".
} 
argumentation tools.

\section{Definitions and Reality}

The crucial relationship between definitions and states of affairs affecting our decisions can be understood from cases in which the association usually taken for granted is challenged. This strategy can be used effectively to modify the application of a legal provision. By redefining a term in a legal statement, it is possible to broaden or to narrow its scope, so that the outcome of this interpretational process is as a matter of fact a new norm. A clear example is from a recent article in the Economist (October 25, 2104, p. 11), illustrating the view that American firms are being "tortured by red tape and taxes to an unprecedented degree."

Case 2

The Environmental Protection Agency (EPA) wants to define "the waters of the United States" to include not just navigable rivers and lakes but also their tributaries. The National Federation of Independent Business (NFIB), a lobby for small firms, howls that this could include ponds and ditches that are dry most of the year. It predicts that developing such land could require permits costing tens of thousands of dollars and long delays.

In case 2 it is possible to identify the two opposed sides of the argument. The EPA has put forward a definition of "the waters of the United States," and the NFIB has attacked this definition by arguing that adopting this definition in public policy would have negative consequences. The NFIB argument basically has three steps. The first step is the proposition (N1) that the new definition could include ponds and ditches that are dry most of the year. Why would this inclusion be bad? The answer is provided by the second step which states two propositions (N2) developing such land would be costly and (N3) it would cause long delays. Both of these consequences are taken to be negative, and hence we can reason backward from them to the conclusion that the policy of adopting the new definition is also negative, not a policy to be accepted. The article does not tell the reader the details of the definition put forward by the EPA, which can be found at the EPA website ${ }^{2}$ :

For purposes of all sections of the Clean Water Act, 33 U.S.C. 1251 et seq. and its implementing regulations, subject to the exclusions in paragraph $(\mathrm{t})$ of this section, the term "waters of the United States" means:

(1) All waters which are currently used, were used in the past, or may be susceptible to use in interstate or foreign commerce, including all waters which are subject to the ebb and flow of the tide;

(2) All interstate waters, including interstate wetlands;

(3) The territorial seas;

(4) All impoundments of waters identified in paragraphs (s)(1) through (3) and (5) of this section;

(5) All tributaries of waters identified in paragraphs (s)(1) through (4) of this section;

(6) All waters, including wetlands, adjacent to a water identified in paragraphs (s)(1) through (5) of this section; and

(7) On a case-specific basis, other waters, including wetlands, provided that those waters alone, or in combination with other similarly situated waters, including wetlands, located in the same region, have a significant nexus to a water identified in paragraphs (s)(1) through (3) of this section.

It is interesting to see that right on the main web page of the site six EPA arguments are presented in favor of the definition:

(E1) Reduces confusion about Clean Water Act protection

(E2) Clarifies types of waters covered under Clean Water Act

(E3) Saves businesses time

(E4) Saves businesses money

(E5) Provides more benefits to public than costs

(E6) Helps states to protect their waters

For the purposes of our analysis, we have broken the third EPA argument down into two component arguments,

\footnotetext{
${ }^{2} \mathrm{http} / / /$ www2.epa.gov/sites/production/files/2014-06/documents/proposed_regulatory_wus_text_40cfr230_0.pdf_(Retrieved on 20 December 2014).
} 
E3 and E4. An argument diagram displaying the pro and con arguments is shown in figure 1.

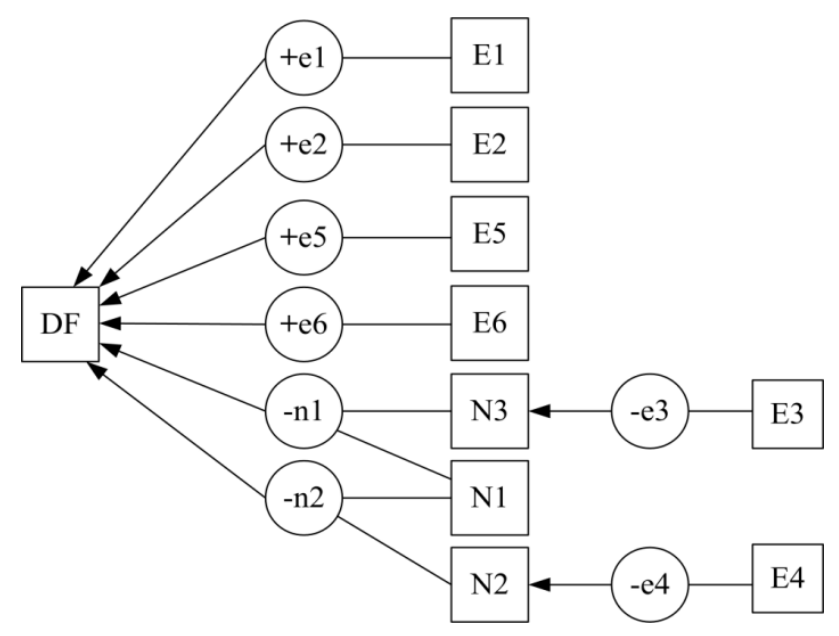

Figure 1. Pro and con arguments in the waters of the United States example

The analysis of the case is displayed in the format of the argument visualization tool of the Carneades Argumentation System (CAS). Propositions making up the premises and conclusions of the arguments are shown in boxes. Arguments are shown in round nodes of the graph. The proposition at the left side of the diagram, labeled DF, represents the EPA statement of the definition. A pro argument is represented by a plus sign in its argument node, while the con argument is represented by a minus sign in its argument node. Four of the pro arguments put forward by the EPA, $+\mathrm{e} 1,+\mathrm{e} 2,+\mathrm{e} 5$ and $+\mathrm{e} 6$, are shown at the top of the diagram.

Each of the four pro arguments of the EPA shown at the top left has a single premise supporting it. At the bottom, the two con arguments put forward by the NSB are shown. Each of them fits the argumentation scheme for argument from negative consequences. These two arguments share a common premise N1, the statement that the new definition could include ponds and ditches that are dry most of the year. Another way that the EPA could use to counterattack the two NSB arguments shown at the bottom is to attack their common premise N1. This counterattack, however, is not put forward in the text of discourse of the case given above, but it has been used on the EPA webpage in defense of its definition.

There are four main lessons to draw from the analysis of case 2 . The first is that the issue in the case is the definition. More specifically, it is about whether a proposed redefinition of the expression "the waters of the United States" should be accepted or not. The second lesson is that the definition, and the issue about revising it, is important for practical purposes. The NSB claims that putting this definition into law would have significant economic consequences. The third lesson is that arguments are presented on both sides pro and con the proposed redefinition. This third lesson is often difficult to get a general audience to grasp, because it is widely assumed that definitions are arbitrary or set into place by fiat, in such a manner that seems to make it not worthwhile to contest them, or to evaluate them as issues that should be contested or reevaluated by weighing pro arguments against con arguments. The fourth lesson is that, as shown by the analysis visualized in figure 1, definitions can be analyzed and evaluated using standard argumentation tools of the kind that are now being widely applied to arguments used in natural language discourse.

\section{Definitions and Evaluations}

Definitions play a crucial role in political discourse for two reasons. On the one hand, they are instruments for classifying a state of affairs, and consequently for applying a rule to a case. By modifying a definition, a legal text can result in broader or narrower rules, with different legal consequences. On the other hand, names can become the premises of tacit arguments supporting specific conclusions. The classification of a state of affairs as "peacekeeping" or "war" can lead to conflicting conclusions based on very different values ("to keep peace is our duty" or "wars should be always avoided"). The definitions that assign to such terms the same reference are generally taken for granted, even when they can be controversial. These implicit and condensed arguments can play a fundamental role in political discourse, especially when some policies need to be justified or argued for before the public.

The relationship between a name, its definition, and the evaluation of the state of affairs it prototypically or 
actually refers to can be understood from a case in which this very relation became controversial and became the subject matter of argumentative reasoning. In a letter to The Economist (August 9, 2014, p. 14), Dr. Robert Wood suggested that the term "suicide" has a stigma attached to it, but since legislators and physicians must deal with the palliative needs of terminally ill patients, some other term is needed to describe the option of ending one's life in circumstances of pain and misery in a terminal illness. To fulfill this terminological need, a number of euphemisms are currently in common use to describe this option in terms other than those such as "suicide" or "euthanasia," which have such negative connotations. Terms such as "death with dignity," "compassion in dying," "medical assistance at the end of life," and "physician-assisted death" have been proposed. Wood proposed the term "aid in dying." The part quoted below is case 3.

Case 3

It is important to distinguish what most people think of as "suicide" from the self-administration of life-ending medications. In the states of Oregon and Washington, if two doctors agree that an adult is within six months of dying, competent to make medical decisions, informed of all the options without coercion, and is able to self-administer the medicine, then one of those doctors may prescribe life-ending drugs for the patient to ingest. This is "aid in dying" and legally it is not deemed to be "suicide". The death certificates of those who die in this manner list the terminal illness as the cause of death. For someone to assist in another person's true suicide remains illegal in Washington.

Notice that in the last sentence of this quotation a distinction is drawn between "true suicide" and "aid in dying." The use of the term "true" in this fashion is known as an indicator of putting forward a persuasive definition (Stevenson, 1994). What is apparent therefore it is that, comparably to the first example, argument and definition are being combined. However in case 3, the relationship between the two is more subtle.

Case 3 illustrates the reframing of an issue of wide public controversy and ethical significance by changing the language in which the issue is framed. Traditionally the issue has been framed as the so-called euthanasia issue in ethical discussions. More recently the term "euthanasia" has been replaced by the term "physician-assisted suicide." But both terms have negative connotations for a general audience. In particular, the latter phrase contains the word "suicide," providing a difficulty for those who want to move forward and change policies and laws to make physician-assisted suicide possible. There is also a single problem with advocating such a policy because in many jurisdictions committing suicide, or assisting someone else to commit suicide, say by providing the medications required, is illegal. Reframing the issue, by replacing these terms with the new term 'aid in dying,' as advocated in this case, circumvents these difficulties.

The strategy illustrated in case 3 is for the advocate on one side of a contested issue of wide political and legal significance to reframe the issue itself by changing the language in which the issue is formulated.

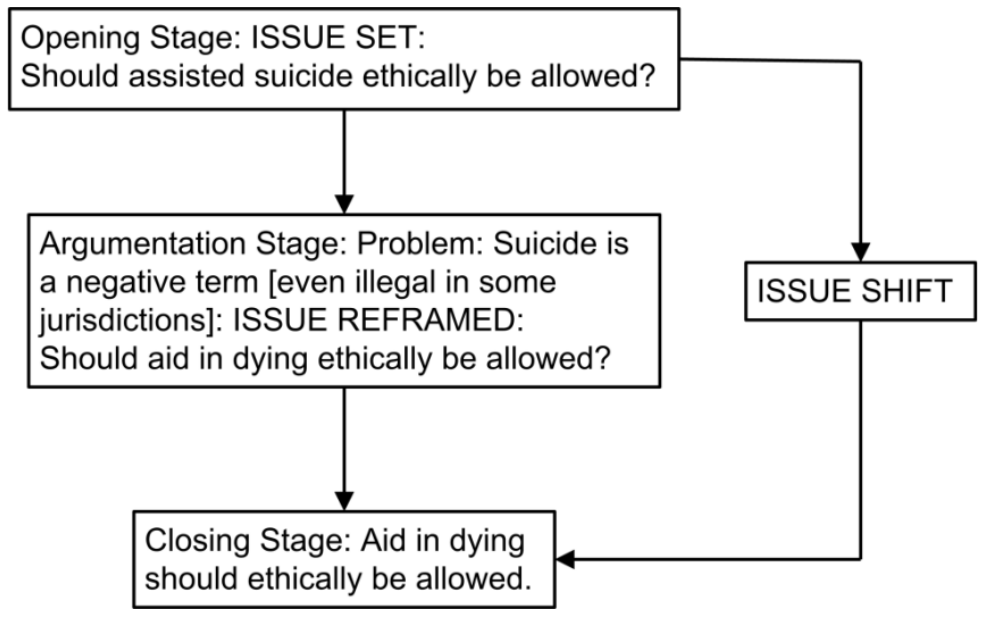

Figure 2. Definitional shift during the argumentation stage

This strategy is a form of argumentation, and in fact a very powerful one, that can make it much easier for one's own side to move ahead towards gaining support for its proposal, and at the same time make it much harder for its opponents to find counter arguments that will be accepted by the audience. But the most interesting aspect of such a case is its subtlety. The strategy is powerful because the audience may be aware unaware that the issue 
has been reframed using value-laden language. Stevenson (1994) was prominent in attempts to identify this rhetorical phenomenon and explain how it works as a powerful argumentation strategy, but argumentation studies (Schiappa, 2003; Macagno \& Walton, 2014) have built on Stevenson's work to apply the concept of persuasive definition the case of this sort.

The sequence of argumentation over which the shift in the reframing of the definition occurs in case 3 is shown in figure 2. There is nothing wrong with reframing an issue if the proper arguments supporting the shift are brought forward by one side and accepted by the other side. The problem with many persuasive definitions of this sort, however, arise when the other party (and the party itself, sometimes) are not aware of the shift, or of the shift in values due to the emotive nature of the key term involved.

\section{Framing and Persuasive Redefinitions}

Quasi-definitions and persuasive definitions represent two distinct and interconnected strategies of framing, in which some specific aspects of a state of affairs are selected and presented as the most important or relevant ones. The distinction between the two strategies lies in what is taken for granted and what is redefined. In persuasive definitions, the speaker modifies the "descriptive meaning," that is, what the definiendum means, narrowing or broadening its reference, so that some objects or notions normally denoted by it are excluded or others not referred by it are included. Persuasive definitions are used to modify how reality is classified, and the change in classification leads indirectly to a change of judgments on the state of affairs referred to by the definiendum. Quasi-definitions do not involve the meaning of the definiendum, which is taken for granted and is not altered directly. Instead, they aim at providing an insight on the alleged "real nature" of the object or notion denoted by the word (Schiappa, 2003, p. 35). In this sense, they pretend to be real definitions, and they are used to modify how the referent of the definiendum is assessed. For example, "welfare" was quasi-defined as a "helping hand" for those in poverty, or as a "government handout" that encouraged dependency; foreign engagements can be quasi-defined as "tools for promoting American values and interests abroad," "foolish wastes of taxpayer dollars," or "humanitarian gestures to the needy of the world" (Nelson \& Oxley, 1999, p. 1041).

The strategies of redefinition need to be strictly related with their effects, that is, with the way the goals of the proponents of the new persuasive definitions or quasi definitions are achieved. The development of a particular judgment on, or conceptualization of an issue, resulting from the orientation or reorientation of attitudes, is analyzed under the label of framing (Chong \& Druckman, 2007, p. 104). Framing can be considered as a goal-directed description aimed at making specific features of a complex state of affairs more accessible (Entman, 1993, p. 52):

Framing essentially involves selection and salience. To frame is to select some aspects of a perceived reality and make them more salient in a communicating text, in such a way as to promote a particular problem definition, causal interpretation, moral evaluation, and/or treatment recommendation for the item described.

A piece of information is made accessible and meaningful, namely salient (Entman, 1993, p. 53), to the audience, so that the interlocutors rely mostly, or only, on it in assessing the state of affairs (see Lakoff, 2010; Heink \& Jaz, 2014). Some of its characteristics that can support the desired evaluation are amplified or stressed, while others eliciting unwanted judgments are omitted.

Framing is grounded on the idea that a value judgment on an entity or a state of affairs depends on the perspectives from which it is viewed. Different points of view are relevant for distinct values or considerations (Chong \& Druckman, 2007, p. 105):

An attitude toward an object, in this view, is the weighted sum of a series of evaluative beliefs about that object. Specifically, Attitude $=\sum v i * w i$, where $v i$ is the evaluation of the object on attribute $i$, and $w_{i}$ is the salience weight $\left(\sum w i=1\right)$ associated with that attribute. For example, one's overall attitude, $A$, toward a new housing development might consist of a combination of negative and positive evaluations, $v_{i}$, of the project on different dimensions $i$. An individual may believe that the project will favor the economy $(i=1)$ but harm the environment $(i=2)$. Assuming this individual places a positive value on both the economy and the environment, then $v_{1}$ is positive and $v_{2}$ is negative, and his attitude toward the project will depend on the relative magnitudes of $v_{1}$ and $v_{2}$ discounted by the relative weights $\left(w_{1}\right.$ and $w_{2}$ ) assigned to each attribute.

On this view, an attitude towards an object can be influenced by making new beliefs available, or increasing the accessibility of existing beliefs, or making a certain belief stronger or more applicable than others (Chong \& Druckman, 2007, p. 110). In this sense, framing can alter the accessibility of certain values or considerations, 
making a specific value or set or values assume priority in one's opinion (Nelson \& Oxley, 1999, p. 1043). The emphasis on a specific dimension of an issue can make a value more accessible than others, and suggest a specific judgment based thereon. An example will be given section 6 and its lesson will be summarized in section 7.

Clearly, the emphasis can affect the availability and the accessibility of values, which can in turn influence a person's hierarchy of values when specific circumstances occur, for instance when the values and the considerations that are taken into account are not consistent, or when the individual does not strongly hold a specific hierarchy of values concerning an issue (Sniderman, 2004, p. 138). In political discourse, quasi-definitions can be powerful tools to affect the judgments of people not holding strong views on an issue, or not having enough information for defending a specific view. In such cases, this definitional strategy provides accessible and condensed arguments that can be easily understood and used to support a view.

\section{Framing and Types of Quasi-definitions}

Persuasive definitions and quasi-definitions represent two different strategies of influencing the evaluative process regarding a state of affairs. In the first case, the definiens modifies the commonly accepted definition of a concept, restricting or broadening it to support a specific conclusion. Quasi-definitions cannot be properly called definitions, as they are statements that do not express an equivalence of meaning, but rather describe the referent by pointing out specific characteristics that trigger a specific (positive or negative) value judgment. In political discourse, quasidefinitions can be used as powerful strategies for framing policies that need to be presented, supported, or attacked before the public. Instead of illustrating the details of a proposal, the speaker can opt to provide the audience with a shortcut, a heuristic route to the desired conclusion. Different tactics can be used to quasi-define a term, corresponding to distinct definitional statements. We will illustrate them in the following subsections by showing how quasi-definitions have been used in the Italian political debates (and in particular in the debate on the Jobs Act) to lead the public to draw specific conclusions heuristically.

\subsection{Definition by Difference}

The ideal model of the definition by genus and difference provides a "structuralist" explanation of meaning, in which one meaning is connected with others by specific similarities and differences, determining the networks of oppositions or contrasts. This type of definition is extremely powerful from a dialectical point of view. However, it is extremely hard to provide and can be rejected by pointing out possible exceptions. The simpler idea of defining a concept by distinguishing it from another based on a difference can be more easily used to counter apparent similarities and bring to light a difference that can be used argumentatively (Liber de Definitionibus 21, $21-24 ; 22,1)$. For example, instead of defining what "tyrant" means, it is possible to point out how a tyrant is different from a king, stating for instance that while the latter is modest and self-controlled, the former is cruel. Clearly, the choice of selecting the allegedly contrary and similar concepts is strategically aimed at drawing a conclusion based on the topic from differences or contraries, which states that what is said of a concept is not suitable to its contrary (Boethius, In Ciceronis Topica 1074a, 1072d). For example, in order to counter the view that kings are like tyrants and should be disapproved of, the definition by difference points out the respect under which they are different, relevant for attacking the conclusion (tyrants shall be disapproved of because of cruelty, which is not a characteristic of kings, who should not be disapproved of). This definition can be extremely powerful, as it allows the speaker to suggest a double conclusion, one supporting a positive judgment on a state of affairs, the other a negative one on its contrary. In case 4, we consider the following statement made by the Italian Prime Minister Renzi during an interview on a TV show, referring to his plans of making substantial reforms (including reforms to the labor laws) (authors' translation) ${ }^{3}$ :

Case 4

The date is the difference between a dream and a project.

Renzi points out that while he is indicating specific deadlines by which he intends to complete his reforms, his predecessors only talked loosely about future plans, without doing anything in practice. Renzi suggests a negative judgment on the previous government (they are dreamers) while drawing a positive one on his plans (they are concrete and they will be done).

Definition by difference can be strategically used to emphasize the similarity between two concepts usually considered as different, transferring the judgment commonly associated with the definiens onto the definiendum. Case 5 below is the following definition of "businessman" given by Grillo when talking about the crimes of the

\footnotetext{
${ }^{3}$ http://www.youdem.tv/doc/265965/renzi-la-data-ci-che-fa-la-differenza-tra-un-sogno-e-un-progetto.htm (Retrieved on November 10, 2014)
} 
rich (referring implicitly to the government class and the previous Italian Prime Minister) (Grillo, 2006, p. 77) (authors' translation):

Case 5

The only difference between a professional thief and a businessman is that the businessman thinks of himself as a good person. He is an excellent person. And there is always someone worse than him. Such as when the Chairman of the Court told Totò Riina, "You used to rape kids," he replied "And what are they doing in Bosnia, your Honor?" The judge was speechless.

In case 5, Grillo uses this definition by difference to equate a businessman with a thief, and transfer the negative judgment associated with the latter onto the former. Moreover, by setting out the difference, he emphasizes the negative character of businessmen, underscoring their hypocritical and ruthless nature.

\subsection{Definition by Analogy}

One of the most strategically powerful types of definitional statement is the definition by analogy, called by Victorinus "iuxta rationem" or proportion of relationships (Victorinus, Liber de Definitionibus 28, 6-7). The famous definition of man as a smaller world is a clear example of this definition, which can be used for clarification (the parts of the world - earth, water, fire, air - correspond to the parts of the man - bones, blood, warmth, soul) or argumentation purposes (the world has been created by God; therefore, man has been created by God as well). The strategic force of this type of definition lies in the analogical inferences that can be drawn from it based on the topic that "regarding similar, the judgment is one and the same" (Boethius, De Topicis Differentiis 1197B 27-28). This definition can be used to emphasize a specific characteristic of the definiendum without providing reasons supporting it. In case 6 , the following definition by analogy was given by the Italian prime minister, Matteo Renzi, to describe article 18 of the Statute of workers (making it prohibitively expensive to fire or lay off workers who are on a permanent contract in companies employing more than 15 people) (author's translation) ${ }^{4}$ :

Case 6

I do not fear new leftists. Art. 18 is a telephone token in an I-Phone.

In case 6, the conclusion of this "quasi-definition" is not argued for, but simply suggested by the analogy and more specifically the abstract category or functional genus (Macagno \& Walton, 2009; Macagno 2014) under which the two relations between terms of the comparison fall, namely "inadequate because obsolete."

\subsection{Definition by Metaphor}

A definition similar to the analogical one is the definition by metaphor, called by Victorinus "per translationem" (Liber de Definitionibus 22, 8-9; Cicero, Topica VII, 32, 2-5), whose classical example is adolescence defined as the flower of age. Both Cicero and Victorinus pointed out that his type of definitional statement is particularly useful for attacking or praising purposes, or for classifying positively or negatively the definiendum. The metaphorical definition is grounded on analogical reasoning (Macagno \& Zavatta, 2014); however, unlike analogical definition it is not focused on a proportion of relations (the properties of the definiendum), but rather on a new pragmatic generic category that becomes the new definitional genus of the definiendum. On this perspective, metaphors redefine the topic pragmatically and contingently. A clear example, case 7 below, drawn from the Italian debate on article 18 of the Statute of Workers, was provided by Matteo Renzi in a television interview 5

Case 7

Art. 18 is talked about as if it were the biggest problem or the biggest opportunity. It is nothing like that. It is a big ideological totem around which the usual insiders dance.

In this quasi-definition, the article becomes an object of superstition and worshipping, which is exploited by the ones that know the matter and is worshipped by ordinary people. This metaphorical definition is extremely powerful from an argumentative perspective, as it leads to different conclusions proceeding from the topics of species-genus ("all the attributes that belong to the species belong to the genus as well", Aristotle, Topics 111a17-32) and genus-species ("whatever is present to the genus is present to the species", Boethius, De Topicis

\footnotetext{
${ }^{4}$ http://www.huffingtonpost.it/2014/10/26/leopolda-ultimo-giorno_n_6048762.html (Retrieved on November 10, 2014)

${ }_{5} \mathrm{http} / /$ www.unita.it/politica/ranzi-tg4-articolo-18-totem-cgil-pd-partito-democratico-m5s-politica-grillo-lavoro-1.540689 (Retrieved on November 10, 2014)
} 
Differentiis 1188B 21-22) ${ }^{6}$.

Table 1. Metaphorical definition as a species of reasoning

\begin{tabular}{ll}
\hline Rule of inference & Example \\
\hline All the attributes that belong to the species belong & $\begin{array}{l}\text { A totem is an object of superstition that can be used } \\
\text { manipulatively. } \\
\text { to the genus as well. }\end{array}$ \\
Therefore, an object of superstition can be used \\
manipulatively by the insiders. \\
Whatever is present to the genus is present to the \\
species.
\end{tabular}

Given the inherent vagueness of metaphorical meaning, resulting from possible various interpretations of the vehicle, it is possible to suggest a conclusion (the most adequate from the point of view of discourse coherence) that can be easily retracted.

\subsection{Definition by Example}

A powerful strategy of quasi-definition is the inductive definition, called by Victorinus $\omega \varsigma$ tó $\pi$ os (Liber de Definitionibus 26, 8). Instead of explaining the meaning of the definiendum, the speaker provides a typical instance of it, which can be a more specific concept ("animal" is a being like man) or a specific instance of it ("man" is a being like John). This type of definition can be extremely powerful for providing accessible information from which the interlocutor can abstract the meaning of the concept to be defined. However, the abstraction process can be influenced and guided by the selection of the examples used in the definitional statement. Depending on the purpose of the definition, the choice of what is most representative changes. For example, a definition by example of "endangered species" usually includes the panda or the koala, or big fish such a species of whales or sharks, but never little fish, amphibians, or rats such as the blob fish, the axolotl, or the kangaroo rat. While the former are more accessible (broadcasted on TV or newspapers) given their nice look, size, or physical power, the latter are simply unknown and ignored. A negative value judgment on policies threatening the environment would be more easily triggered by commonly known and positively valued examples than from unknown instances that may lead to ambivalent judgments. Similarly, if we want to define by example what a dangerous animal is we provide the examples of the lion, the shark or the crocodile, but do not mention the mosquito or the hippopotamus, which are usually regarded as familiar and innocuous, or cute and funny.

Definition by example is particularly powerful in political discourse, where the speaker can quasi-define a concept by choosing the instance that better suits his communicative goal. In case 8 , in the Jobs act debate Grillo provided the following quasi-definition of the concept under discussion, drawing on the German case (authors' translation $)^{7}$ :

Case 8

The Germans have applied the Jobs act, and it did not work. It means to take a person who has a normal job, to lay him off, and hire three temporary workers to do his job, so that the salaries can be reduced.

Grillo defines the policy by mentioning the German case, and more specifically a deviant instance of its application in which three temporary workers are underpaid and a permanent one dismissed. This example can easily suggest negative conclusions that are then generalized to the whole idea of the Jobs act in any country.

\subsection{Definition by Effect}

An extremely powerful instrument for pointing out the aspects of a concept relevant to supporting an evaluative judgment is the definition by cause-effect, called by Victorinus (Liber de Definitionibus 18, 11-12) "per notionem." For example, "providence" can be defined as the capacity through which the mind sees what is going

\footnotetext{
${ }^{6}$ In Latin: "quae generi adsunt speciei adsunt."

http://www.rainews.it/d1/rainews/articoli/festa-m5s-grillo-show-renzi-un-leader-senza-base-il-jobs-act-licenzia-d7cc4fcd-9c1a-42fc-8323-31 d685eb8f78.html (Retrieved on November 10, 2014)
} 
to happen before it happens (Cicero De Inventione, II, 160), or "consul" as "to behave with honor and conduct, and defend the interest of the state." By describing a concept through its causes or effects, it is possible to connect it with experience, and point out possible discrepancies between an instance and the ideal model. The quote below is from (Cicero, In Pisonem X, 23.5-10):

One cannot be a consul without spirit, conduct, honour, gravity, vigilance, care; without discharging, in a word, every duty of his office, by defending, and above all, by consulting the interest of the state, which is implied in the very name. Shall I look upon him as a consul, who did not think there was a senate in the republic?

The ideal behavior as a consul (one is a consul if carries out certain actions in a certain way) is compared with Piso's behavior, and by attacking the behavior also the classification as a consul is denied. The definition by effect can be used to highlight the possible or actual effects of the state of affairs referred to by the definiendum, triggering an argument from negative or positive consequences. Example 9 is the following definition given by the Italian Prime Minister, Renzi, of Article 18 of the Statute of Workers, protecting the employees from unjust dismissals $^{8}$ :

Case 9

Article 18 is apartheid between series A and series B workers.

Renzi quasi-defines the legal provision using a metaphor describing one of its effects, namely discriminating between workers with permanent contracts and the ones employed temporarily. By focusing on this effect of the article, he can suggest the conclusion that it is unjust and for this reason should be abolished in name of equality.

\subsection{Quasi-definitions and Framing}

Quasi-definitions do not change our classification of reality, but they do change the way we evaluate it. Quasi-definitions can be conceived as different strategies of framing an issue, making some dimensions more accessible than others and reducing a complex issue to assessment by taking into account one or few non-conflicting values. In case 7, the quasi-definition of the Italian Jobs Act as a "totem" or in case 9 as "apartheid" provides a summary in the form of a slogan of arguments based on complex considerations, and isolates the values of "updating the Italian labor market" or "defending the equality of all workers" from all the other possible values that this issue involves, such as the protection of workers' rights. While a specific definition or quasi-definition isolates a value, it cannot delete other ones that the interlocutor holds and that may compete with it. The potential effectiveness of a quasi-definition depends on how the principles consistent with the ones advocated by it are shared, and whether the non-consistent ones are stronger or more commonly held. The balance between the consistent and non-consistent values draws lines between the possible effects of a quasi-definition.

In case 9, Renzi's quasi-definition of the Article 18 as apartheid sounded scandalous to the supporters of workers' rights, but advanced a powerful argument pointing out a shared view of the Italian labor market, in which temporary workers have little or no rights contrary to employees holding permanent contracts ${ }^{9}$. Grillo's definition of 'businessman' can be accepted because it was uttered by a comic actor known for his hasty generalizations, and because they were based on several scandals involving blue collar workers. The comic effect, based on the presumption that such a quasi-definition is considered as an exaggeration, is elicited by the same conflict of values that would have otherwise resulted in a controversy. When the distance between the values pointed out in the definitional statement overtly conflict with the shared ones, the definition can simply result in a scandal or be received as a joke or nonsense. Soradaci's quasi-definition of spies mentioned above can be considered as funny, but not persuasive or capable of affecting the usual judgment on spies, given the background values commonly associated with it at the time when the autobiography was written.

\section{Conclusions}

The argumentation in this paper follows an inductive method studying phenomena important for argumentation study in a series of cases, drawing conclusions from the analyses using argumentation tools applied to the cases. The most general conclusion we hope to persuade the readers to accept is that the employment of persuasive definitions and quasi-definitions as parts of arguments is far from a trivial matter. The cases easily demonstrate this conclusion, but it is very hard to overcome the commonly held view that definitions are more or less

\footnotetext{
${ }^{8} \mathrm{http} / / /$ ilmanifesto.info/jobs-act-anche-per-decreto-2/ (Retrieved on November 10, 2014)

${ }^{9} \mathrm{http}: / /$ www.repubblica.it/politica/2014/09/16/news/mattero_renzi_le_reazioni_all_informativa_sul_programma_dei_mille_giorni-95873050/ (Retrieved on November 10, 2014)
} 
arbitrary or trivial, and that nothing serious much depends on them.

In section 2 we showed how the notion of a persuasive definition evolving from Stevenson's early work led to the distinction of Macagno and Walton (2014) between persuasive definitions and quasi-definitions. In a persuasive definition the evaluative component is left unaltered while the descriptive meaning is modified. Persuasive definitions change the meaning while keeping the original evaluations evoked by the word. In a quasi-definition, the emotive meaning of the word is changed without altering the descriptive meaning. By using this argumentation strategy the speaker can quasi-define a word without precisely specifying what the term actually means. Case 1 was used as an illustration.

In section 3, we presented a legal example, case 2, which was about the proposed redefinition of the expression "the waters of the United States." Against the commonly held assumptions that definitions are trivial, it was shown in this example how putting the definition into law would have significant economic consequences. It was also shown how the argumentation in the example is not merely putting forward of a definition, but also presents an argument that has a definite spin on it. The example shows clearly that the only way to evaluate the acceptability of such a definition is to look at it as a pair of arguments, pro and con, advocated on both sides of the dialogue on a contested issue. This approach is the general methodology of logical argumentation (Walton, 2013).

In case 3, we presented a controversial public policy issue with legal implications turning on the redefinition of a contested term. We showed in section 4 that this strategy is a form of argumentation, and extremely powerful because the audience may be unaware of how the issue has been reframed using value-laden language.

In section 5 we presented a very brief survey of the recent literature in linguistics showing how quasi-definitions and persuasive definitions both represent strategies of framing an issue by selecting out specific aspects of the discussion that are presented as the most important or relevant ones. In this section it was shown how persuasive definitions and quasi-definitions work in different ways as strategies of reframing an issue. It was shown how reframing is based on the assumption that a value judgment depends on the perspective from which it is viewed in relation to different points of view on a controversial issue. For example, in the aforementioned cases of the debate on article 18, the same state of affairs (the abrogation of a provision of law) can be described (or defined, as in the cases given) selecting one specific point of view, which can correspond to its future negative effects (lower salaries and fewer rights), its present effects (introduce discriminations between workers), or its scope (it is an ideological concept without significant applications). Each perspective triggers different arguments, each based on distinct values (workers' rights; adequate consideration for work; equality of rights between workers; improvement of the economy; pragmatism).

In section 6 we used a series of cases to put forward a classification of five types of quasi-definitions. This typology is not put forward as complete, that is, as exhausting all the possible types of quasi-definitions. But based on the extensive studies of collections of examples of quasi-definitions in (Macagno and Walton 2014), it covers a good deal of the territory. These subspecies of quasi-definitions comprise five categories of definitional argumentation strategies: (1) definition by difference, (2) definition by analogy, (3) definition by metaphor, (4) definition by example, and (5) definition by effect.

Cases 5, 6, 7, 8 and 9 concerned different kinds of quasi-definitions used as parts of the argumentation in the political controversies about the Italian Job Act. These cases showed how use of a quasi-definition can work as a powerful rhetorical tool affects the views and the behavior of an audience. This example shows how the values of the audience can be manipulated by clever uses of quasi-definition persuasive strategies in cases of argumentation having serious legal and political implications.

\section{Acknowledgements}

Fabrizio Macagno would like to thank the Fundação para a Ciência e Tecnologia (FCT), Portugal for the research Grant IF/00945/2013.

Douglas Walton would like to thank the Social Sciences and Humanities Research Council of Canada for the award of Insight Grant 435-2012-0104: The Carneades Argumentation System.

\section{References}

Aristotle. (1991). Topics. In J. Barnes (Ed.). The Complete Works of Aristotle (Vol. 1). Princeton: Princeton University Press.

Boethius, A. M. S. (1978). De Topicis Differentiis. Translated by E. Stump. Ithaca: Cornell University Press.

Boethius, A. M. S. (1988). In Ciceronis Topica. Translated, with notes and Introduction by E. Stump. Ithaca: 
Cornell University Press.

Casanova, G. (1911). Historia della mia fuga dalle prigioni della republica di Venezia dette "li Piombi." Milano: Alfieri e Lacroix.

Chong, D., \& Druckman, J. (2007). Framing theory. Annual Review of Political Science, 10, 103-126. http://dx.doi.org/10.1146/annurev.polisci.10.072805.103054

Cicero, M. T. (1811). Cicero's Select Orations, Translated Into English: With the Original Latin. Translated by W. Duncan. New York: Evert Duyckinck.

Cicero, M. T. (1988). De Inventione. In The Orations of Marcus Tullius Cicero. Translated by C. D. Yonge. London: George Bell \& Sons.

Entman, R. (1993). Framing: Toward Clarification of a Fractured Paradigm. Journal of Communication, 43(4), 51-58. http://dx.doi.org/10.1111/j.1460-2466.1993.tb01304.x

Grillo, B. (2006). Tutto il Grillo che conta: dodici anni di monologhi, polemiche, censure. Milan: La Feltrinelli.

Heink U., \& Kurt, J. (2014). Framing Biodiversity - The Case of "Invasive Alien Species". In D. Lanzerath, \& M. Friele (Eds.), Concepts and Values in Biodiversity (pp. 73-98). London: Routledge.

Huxley, A. (1955). Eyeless in Gaza. London: Chatto \& Windus.

Lakoff, G. (2010). Why it Matters How we Frame the Environment. Environmental Communication, 4(1), 70-81.

Macagno, F. (2014). Analogy and Redefinition. In H. J. Ribeiro (Ed.), Systematic Approaches to Argument by Analogy (pp. 73-90). Cham: Springer.

Macagno, F., \& Walton, D. (2009). Argument from Analogy in Law, the Classical Tradition, and Recent Theories. Philosophy and Rhetoric, 42(2), 154-182. http://dx.doi.org/10.1353/par.0.0034

Macagno, F., \& Walton, D. (2014). Emotive Language in Argumentation. Cambridge: Cambridge University Press. http://dx.doi.org/10.1017/CBO9781139565776

Macagno, F., \& Zavatta, B. (2014). Reconstructing Metaphorical Meaning. Argumentation, 28(4), 453-488. http://dx.doi.org/10.1007/s10503-014-9329-z

Nelson, T., \& Oxley, Z. (1999). Issue Framing Effects on Belief Importance and Opinion. The Journal of Politics, 61(4), 1040-1067. http://dx.doi.org/10.2307/2647553

Orwell, G. (1946). Politics and the English Language. Horizon, April.

Schiappa, E. (2003). Defining Reality. Definitions and the Politics of Meaning. Carbondale and Edwardsville: Southern Illinois University Press.

Sniderman, P. M., \& Theriault, S. M. (2004). The Structure of Political Argument and the Logic of Issue Framing. In W. E. Saris, \& P. M. Sniderman (Eds.), Studies in Public Opinion (pp. 133-165). Princeton, NJ: Princeton University Press.

Stevenson, C. L. (1937). The Emotive Meaning of Ethical Terms. Mind, 46, 14-31. http://dx.doi.org/10.1093/mind/XLVI.181.14

Stevenson, C. L. (1938a). Persuasive Definitions. Mind, 47, 331-350. http://dx.doi.org/10.1093/mind/XLVII.187.331

Stevenson, C. L. (1938b). Ethical Judgments and Avoidability. Mind, 47, 45-57. http://dx.doi.org/10.1093/mind/XLVII.185.45

Stevenson, C. L. (1944). Ethics and Language. New Haven: Yale University Press.

Victorini, C. M. (1997). Liber de Definitionibus, mit Einleitung, Übersetzung und Kommentar von A. Pronay. Frankfurt: Peter Lang.

Walton, D. (2013). Methods of Argumentation. Cambridge: Cambridge University Press. http://dx.doi.org/10.1017/CBO9781139600187

Zarefsky, D. (2006). Strategic Maneuvering through Persuasive Definitions: Implications for Dialectic and Rhetoric. Argumentation, 20, 399-416. http://dx.doi.org/10.1007/s10503-007-9030-6

\section{Copyrights}

Copyright for this article is retained by the author(s), with first publication rights granted to the journal.

This is an open-access article distributed under the terms and conditions of the Creative Commons Attribution license (http://creativecommons.org/licenses/by/3.0/). 